\title{
KẾT QUẢ PHẪU THUÂT UNG THƯ LƯỠI GIAI ĐOẠN III, IV (M0) SAU HÓA CHẤT TÂN BỔ TRỢ TẠI BỆNH VIỆN K
}

\author{
Trần Đức Toàn ${ }^{1,2}$, Đinh Xuân Cường ${ }^{2}$ \\ Ngô Quốc Duy ${ }^{2}$, Lê Thế Đường ${ }^{2}$, Lê Văn Quảng ${ }^{1,2}$
}

\section{TÓM TẮT}

Mục tiêu: Nhận xét đặc điểm lâm sàng, cận lâm sàng, thời gian sống thêm của bệnh nhân ung thư lưỡi giai đoạn III,IV(M0) được phẫu thuật sau hóa chất tân bổ trợ tại bệnh viện $K$. Đối tương nghiên cứu: Bao gồm 63 bệnh nhân (BN) ung thư lưỡi được hóa chất tân bổ trợ sau đó phẫu tại khoa Ngoại Đầu cổ bệnh viện $\mathrm{K}$ trong thời gian từ T1/2014- T12/2020. Phương pháp nghiên cứu: Nghiên cứu mô tả lâm sàng hồi cứu kết hợp tiến cứu. Kết quả: Tuổi trung bình 51,3; nam/ nữ: 3,6/1; phát hiện u tại bờ lưỡi hay gặp nhất $87,3 \% ; 53,9 \%$ u trên $4 \mathrm{~cm}, 79,4 \%$ hạch dưới $3 \mathrm{~cm}$, tỷ lệ dùng phác đồ hóa trị TCF 9,5\% TC $57,1 \%$ CF $33,4 \%$, tỷ lệ đáp ứng hoàn toàn $11,1 \%$, một phần $62,4 \%$, giữ nguyên $26,3 \%$. Phương pháp phẫu thuật chủ yếu cắt nửa lưỡi và vét hạch cổ $61,9 \%$, tỷ lệ biển chứng phẫu thuật thấp , các biến chứng hay gặp nhất là hoai tử vạt và rò nước bot chiếm $4,8 \%$. Sông thêm toàn bộ sau 5 năm là $24,1 \%$, của nhóm giai đoạn III là 48,1\%, nhóm giai đoạn IV 8,1\%. Kêt luận: Ung thư lưỡi thường gặp ở nam giới trung niên, bệnh thường phát hiện ở giai đoan tiến triển. Phẫu thuật là phương pháp điều trị chính. Điều trị hóa chất tân bổ trợ giúp thu gọn u và hạch, tạo thuận lợi cho phẫu thuật. Việc lựa chọn phác đồ hóa trị, phương pháp phấu thuẩt cẳt u và tái tạo khuyết tổn phụ thuộc thể trạng bệnh nhân, kinh nghiệm của bác sỹ điểu trị. Thời gian sống thêm của nhớm giai đoạn III hơn nhóm giai đoạn IV(M0).

Tư khóa: ung thư lưỡi, tân bổ trợ, phẫu thuật lưỡi

\section{SUMMARY \\ RESULTS OF SURGERY IN STAGE III, IV (MO) TONGUE CANCER POST NEOADJUVANT CHEMOTHERAPY}

Objectives: This study was conducted to report clinicals, subclinicals and evaluate the results of surgery in stage III,IV(M0) tonge cancer post neoadjuvant chemotherapy at Vietnam National Cancer Hospital. Patients and methods: A retrospective, descriptive study on 63 patients with neoadjuvant chemotherapy tongue cancer patients were operated in K hospital from $01 / 2014$ to $12 / 2020$. Results: Mean age 51.3; male/female: $3.6 / 1$; the most common position of tumor is the edge of tongue $87.3 \%$; $53.9 \%$ tumor over $4 \mathrm{~cm}, 79.4 \%$ lymph node

\footnotetext{
${ }^{1}$ Trường Đại học Y Hà Nội

²Bênh viên $K$

Chịu trách nhiệm chính: Trân Đức Toàn

Email: tranductoanhmu@gmail.com

Ngày nhận bài: 8.9.2021

Ngày phản biện khoa học: 25.10.2021

Ngày duyệt bài: 8.11.2021
}

less than $3 \mathrm{~cm}$, chemotherapy regimens TCF $9.5 \%$ TC $57.1 \%$ CF $33.4 \%$; Complete response $11.1 \%$, partial reponse $62.4 \%$, stable disease $26.3 \%$. The main surgical method is hemiglossectomy and neck lymph node dissection $61.9 \%$, the surgical complications is rare, the most common complications are flap necrosis and salivary leakage $4.8 \%$. 5 years overall survival was $24.1 \%$, of stage III group was $48.1 \%$, stage IV group was $8.1 \%$. Conclusion: Tongue cancer is common in middle-aged men, the disease is often detected at an advanced stage. Surgery is the main treatment. Neo-adjuvant chemotherapy helps shrink tumors and lymph nodes, facilitating surgery. The choice of chemotherapy regimen, surgical methods of tumor removal and reconstruction depends on the patient's performance status and the experience of the physician. The survival time of the stage III group was higher than that of the stage IV(M0) group.

Keywords: tongue cancer, neoadjuvant, tongue surgery.

\section{I. ĐăT VẤN ĐỀ}

Ung thư lưỡi là bệnh thường gặp nhất trong các ung thư khoang miệng, triệu chứng bệnh ở giai đoạn đâuu không điển hình dẫn đến việc còn nhiều bệnh nhân đến viện ở giai đoạn III, IV ${ }^{1}$. Ở giai đoạn này, phẫu thuật ngay từ đâu là một phẫu thuật lớn đòi hỏi phẫu thuật viên kinh nghiệm, hậu phẫu nặng nề, chức năng nhai, nuốt, nói sau mổ bị ảnh hưởng ${ }^{2}$. Trong khi đó, điều trị hóa chất tân bổ trợ ở giai đoạn III, IV (Mo) giúp thu nhỏ kích thước u và hạch tạo thuận lợi cho phẫu thuật và xạ trị, làm giảm các biến chứng, hạn chế di căn xa. Tại Việt Nam, chưa có nhiêuu nghiên cứu về vấn đề này, đó là lý do chúng tôi thực hiện đề tài nhằm mục tiêu: Nhận xét đặc điểm lâm sàng, cận lâm sàng, thời gian sống thêm của bệnh nhân ung thư lưỡi giai đoạn III,IV(M0) được phẫu thuật sau hóa chất tân bổ trợ tại bệnh viện K

\section{II. ĐỐI TƯỢNG VÀ PHƯƠNG PHÁP NGHIÊN CỨU}

2.1. Đối tượng nghiên cứu. Bao gồm 63 BN ung thư lưỡi giai đoạn III,IV(MO) điều trị phẫu thuật sau hóa chất tấn bổ trợ tại bệnh viện K từ T1/2014- T12/2020.

\section{Tiêu chuẩn lưa chọn}

Bệnh nhân UTL phần di động giai đoạn III, IV (M0) theo AJCC 2010.

- Chẩn đoán mô bệnh học tại u là ung thư biểu mô vảy. 
- Tuổi 18 - 70.

- Chỉ số toàn trạng ECOG 0-2

- Chức năng tuỷ xương còn tốt, chức năng gan thân còn tốt.

- Không mắc bệnh khác có nguy cơ tử vong gần, không mắc bệnh ung thư khác.

- Thông tin hồ sơ đầy đủ

Tiêu chuân loai trừ

- BN không thỏa mãn bất kì một tiêu chuẩn lựa chọn nêu trên

- Ung thư tái phát hoặc mắc ung thư thứ hai.

\subsection{Phương pháp nghiên cứu}

Thiết kế nghiên cứu: Nghiên cứu mô tả lâm sàng hồi cứu kết hợp tiến cứu.

Cỡ mẫu: Bằng phương pháp chọn mẫu thuận tiện, nghiên cứu của chúng tôi thu thập được 63 $\mathrm{BN}$ thỏa mãn tiêu chuẩn lựa chọn và tiêu chuẩn loại trừr.

1.3. Xử lý số liệu. Nhập và xử lý số liệu bằng phần mềm SPSS 20.0.

\section{KẾT QUẢ NGHIÊN CỨU}

3.1. Đặc điểm lâm sàng và cận lâm sàng

Tuổi, giới: Tuổi trung bình 51,3. Nhóm thường gặp nhất 41-60 tuổi. Tỷ lệ Nam/Nữ là 3,6/1

Vị trí: Bờ lưỡi $87,3 \%$, đầu lưỡi 7,9\%, mặt trên lưỡi 4,7\%

Kích thước u trước điêu trị: $53.9 \%$ trên 4 $\mathrm{cm}, 46,1 \%$ dưới $4 \mathrm{~cm}$

Tính chất xâm lấn: Sàn miệng $52,4 \%$, trụ trước amydal 23,8\%, lưỡi cố định 15,9\%, qua đường giữa 7,9\%.

Kích thước hạch: dưới $3 \mathrm{~cm} 79,4 \%, 3-6 \mathrm{~cm}$ $15,9 \%$, trên $6 \mathrm{~cm} 1,6 \%$

Giái phẫu bênh: $100 \%$ là ung thư biểu mô vảy

Phác đồ sử dụng: TCF 9,5\% TC 57,1\% CF $33,4 \%$

Đáp ứng: Hoàn toàn $11,1 \%$, Một phần $62,6 \%$, Giữ nguyên $26,3 \%$

3.2. Kết quả phấu thuật

Bảng 1: Phương pháp phẫu thuật

\begin{tabular}{|c|c|c|}
\hline Phương pháp & $\begin{array}{c}\text { Số } \\
\text { BN }\end{array}$ & $\begin{array}{c}\text { Tỷ lệ } \\
\text { \% }\end{array}$ \\
\hline Cắt nửa lưỡit vét hạch cố & 39 & $61,9 \%$ \\
\hline $\begin{array}{c}\text { Cắt nứa lưỡi+ vét hạch cố + tạo } \\
\text { hình vạt rãnh mũi má }\end{array}$ & 15 & $23,8 \%$ \\
\hline $\begin{array}{c}\text { Cắt nửa lưỡi+ vét hach cố + tạo } \\
\text { hình vạt dưới cằm }\end{array}$ & 5 & $7,9 \%$ \\
\hline $\begin{array}{c}\text { Cắt nưaa lưỡi+ vét hach cố + tạo } \\
\text { hình vạt ngực lớn }\end{array}$ & 2 & $3,2 \%$ \\
\hline $\begin{array}{c}\text { Cắt nưaa lưỡi vét hâch cố + tạo } \\
\text { hình vi phẫu }\end{array}$ & 2 & $3,2 \%$ \\
\hline
\end{tabular}

Nhân xét: Tất cả BN được cắt nửa lưỡi kèm theo vét hạch cố, trong đó $61,9 \%$ đóng trực tiếp, $23,8 \%$ tạo hình vạt rãnh mũi má, $7,9 \%$ tạo hình vạt dưới cằm, 3,2\% tạo hình vạt ngực lớn, 3,2\% tạo hình vi phẩu

Bảng 2: Tỷ lệ đáp ứng hoàn toàn trên mô bệnh họ

\begin{tabular}{|c|c|c|c|}
\hline Phác đố & Số BN & Tỷ lệ \% & P \\
\hline TCF & 2 & $22,2 \%$ & \multirow{3}{*}{} \\
\hline CF & 5 & $15,2 \%$ & \multirow{2}{*}{$\mathrm{N}=0,07$} \\
\hline TC & 3 & $14,3 \%$ & \\
\hline
\end{tabular}

Nhân xét: Tỷ lệ đáp ứng hoàn toàn trên mô bênh học của các phác đồ tương ứng là TCF $22,2 \%$, CF $15,2 \%$, TC $14,3 \%$

Bảng 3: Biến chứng sau phẫu thuật

\begin{tabular}{|c|c|c|}
\hline Biến chứng & Số BN & Tỷ lệ \% \\
\hline Chảy máu & 2 & $3,2 \%$ \\
\hline Nhiêm trùng & 2 & $3,2 \%$ \\
\hline Liệt thần kinh bờ hàm dưới & 1 & $1,6 \%$ \\
\hline Hoại tứ vạt & 3 & $4,8 \%$ \\
\hline Rò nước bọt & 3 & $4,8 \%$ \\
\hline
\end{tabular}

Nhâan xét: Trong 63 BN được phẫu thuật, có $2 \mathrm{Bn}$ chảy máu, $2 \mathrm{Bn}$ nhiễm trùng vết mổ, $3 \mathrm{Bn}$ có hoai tử vat 1 phần hoặc hoàn toàn, $3 \mathrm{Bn}$ có rò nước bọt sau mô.

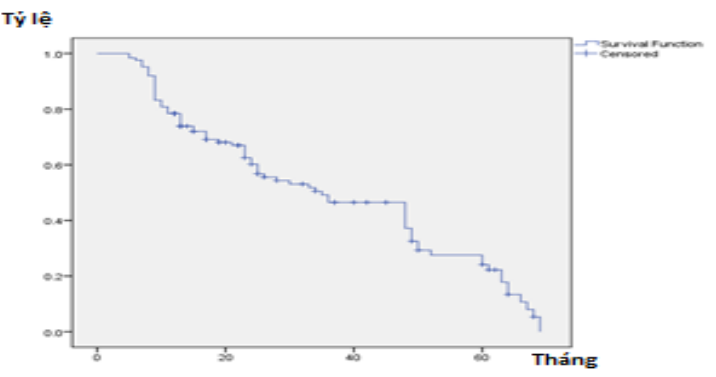

Biểu đồ 1: Thời gian sống thêm

Nhận xét. Sống thêm toàn bộ 1 năm, 2 năm, tương ứng là 78,2\%, 58,6\%

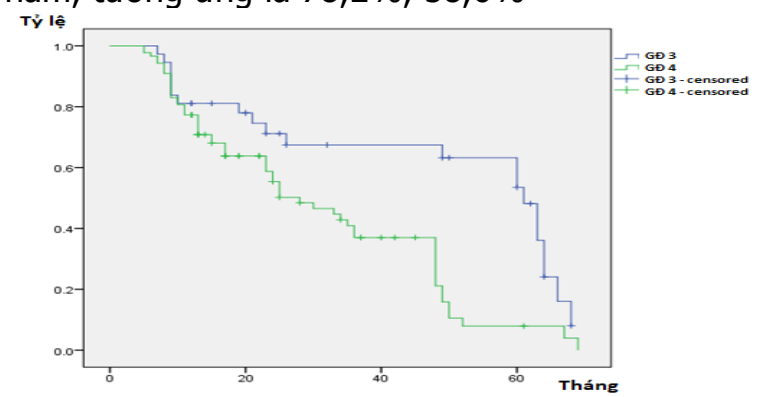

Biểu đồ 2: Thời gian sông thêm theo giai đoạn

Nhận xét: Sống thêm toàn bộ giai đoạn III cao hớn so với giai đoạn IV có ý nghĩa thống kê với $p=0,003$.

\section{BÀN LUẬN}

4.1. Đặc điểm lâm sàng và cận lâm sàng

Tuổi, giới: Trong nghiên cứu của chúng tôi, nhóm tuổi gặp nhiều nhất từ 41-60 tuổi.Kết quá 
này cũng tương tự các tác giả trong và ngoài nước. Nghiên cứu của Listl và cộng sự cho kết quả, lứa tuổi hay gặp nhất là từ 41-60 tuổi, chiếm $46 \%{ }^{3}$

Trong tất cả các nghiên cứu về UTL đều cho thây nam mắc nhiều hơn nữ, lý do có thể là do nam giới chịu nhiều ảnh hưởng của các yếu tố nguy cơ gây UTL như hút thuốc, uống rượu,... Trong nghiên cứu của chúng tôi tỷ lệ nam/nữ = $3,6 / 1$, phù hợp với nghiên cứu của Pergolizzi (2013) tiến hành trên 6.241 bệnh nhân ung thư lưỡi, tỷ lệ nam/nữ là $2,88 / 1^{4}$.

Vị trí u: Ung thư lưỡi phần di động hay gặp ở bờ tự do của lưỡi, sau đó đến mặt dưới lưỡi, ít gặp vị trí đâu lưỡi. Lý do có thể là ung thư lưỡi có liên quan đến các bệnh lý mãn tính vùng răng miệng dẫn tới hay gây tổn tương ở bờ lưỡi gây ra tổn thương mãn tính và tữ đó dẫn tới ung thư.

Kích thước u: Nghiên cứu của chúng tôi tập trung ở nhóm bệnh nhân giai đoạn III, IV (MO) chưa thể phẫu thuật được ngay nên kích thước khối u thường lớn.Cùng chung nhóm đối tượng nghiên cứu như trên, tác giả Ngô Xuân Quý cho kết quả tương tự với tỷ lệ u > 4cm là 45,6\%

Tính chất xâm lấn u: Đây là một đặc điểm rất quan trọng quyết định khả năng phấu thuật được và mức độ rộng rãi của phẫu thuật, phương án tạo hình. Chủ yếu gặp u xâm lấn sàn miệng 52,4\%.

Kích thước hạch: $79,4 \%$ hạch kích thước dưới $3 \mathrm{~cm}$ tương tự nghiên cứu của Ngô Xuân Quý. Thường gặp hạch di căn nhóm 1,2,3 cùng bên tổn thương lưỡi.

Phác đồ sử dụng: Tỷ lệ sử dụng các phác đồ trong nghiên cứu của chúng tối lần lượt là TCF 9,5\% TC 57,1\% CF 33,4\%. Việc lựa chọn phác đồ tùy thuộc vào thể trạng bệnh nhân và kinh nghiệm của nhà hóa trị. Nghiên cứu của tác giả Zhong (2013) cho thây tỷ lệ đáp ứng chung của phác đồ TCF lên tới $80 \%$, tuy nhiên biến chứng cũng nhiều hỡn so với 2 phác đồ còn lại ${ }^{6}$.

\subsection{Kết quả phẫu thuật}

Phương pháp phẫu thuật: Tất cả bệnh nhân được phẫu thuật cắt nửa lưỡi, vét hạch cổ.Trong đó, $61,9 \%$ đóng trực tiếp, còn lại được tái tạo khuyết tổn bằng các vạt có cuống hoặc tự do gồm: vạt rãnh mũi má, vạt dưới cằm, vạt ngực lớn, vạt đùi trước ngoài. Việc dùng các vạt tái tạo lại khuyết tổn giúp bệnh nhân nhanh phục hồi các chức năng nói, nuốt, tuy nhiên có nhược điểm là làm kéo dài thời gian gây mê phẫu thuật và làm biến dạng nơi cho vạt. Việc lựa chọn phương pháp tái tạo phụ thuộc vào các yếu tố: tính chất khuyết tổn, kinh nghiệm phẫu thuật viên, thể trạng bệnh nhân và nguyện vọng bệnh nhân.

Giải phẫu bệnh sau mổ: Phác đồ TCF có tỷ lệ đáp ứng hoàn toàn trên mô bệnh học cao nhất $22,2 \%$. Tuy nhiên, sự khác biệt về tỷ lệ đáp ứng hoàn toàn trên mô bệnh học không có sự khác biệt so với 2 phác đồ còn lại. Theo Vokes, 2 phác đồ $\mathrm{CF}$ và $\mathrm{TC}$ tương đương về tỷ lệ đáp ứng cũng như thời gian sống thêm sau mổ. Theo Zhong, thời gian sống thêm toàn bộ của nhóm đáp ứng hoàn toàn cao hơn đáng kể so với nhóm còn lạị,

Biến chứng sau mổ: Chảy máu và nhiễm trùng tại chố ít gặp chiếm tỳ lệ: $3,2 \%$. Biến chứng nhiễm trùng găp trên bệnh nhân đái tháo đường, được xử trí bằng kháng sinh, chăm sóc tại chố và kiểm soát đường huyết. Tý lệ hoại tử vạt chiếm $4.8 \%$, các bệnh nhân có hoại tử vạt một phần được cắt lọc, chăm sóc tại chố, 1 bệnh nhân hoại tử vạt hoàn toàn được phấu thuật tạo hình lại thì 2. Tác giả Schwam cho rằng hút thuốc là một trong những yếu tố nguy cơ xảy ra biến chứng ở bệnh nhân phẫu thuật ung thư khoang miệng9 .

Thời gian sống thêm: Thời gian gian sống thêm toàn bộ 12 tháng là $78,2 \%$, sau 24 tháng $58,6 \%$, sau 36 tháng $46,5 \%$, sau 48 tháng $37,2 \%$ và sau 60 tháng là $24,1 \%$. Kết quả này tương đương nghiên cứu của Pergolizzi tỷ lệ bệnh nhân sống thêm toàn bộ tại thời điểm 3 năm, 5 năm lần lượt là $37 \%$ và $26 \%$. Vokes cho kết quả tỷ lệ sống thêm toàn bộ tại thời điểm 2 năm, 3 năm lần lượt là toàn bộ là $77 \%$ và $70 \%{ }^{4,7}$. Thời gian sống thêm của nhóm giai đoạn III cao hơn nhóm giai đoạn IV có ý nghĩa thống kê. Các kết quả này cũng tương tự nghiên cứu của Lê Văn Quảng, Ngô Xuân Quýs,io .

\section{KẾT LUẬN}

Ung thư lưỡi thường gặp ở nam giới trung niên, bệnh thường phát hiện ở giai đoạn tiến triển. Phẫu thuật là phương pháp điều trị chính. Điều trị hóa chất tân bổ trợ giúp thu gọn u và hạch, tạo thuận lợi cho phẫu thuật. Việc lựa chọn phác đồ hóa trị, phương pháp phẫu thuật cắt u và tái tạo khuyết tổn phụ thuộc thể trạng bệnh nhân, kinh nghiệm của bác sỹ điều trị. Thời gian sống thêm của nhớm giai đoạn III hơn nhóm giai đoạn IV(M0).

\section{TÀI LIÊU THAM KHẢO}

1. Lê Văn Quảng (2020). Ung Thư Đầu Cổ. Nhà xuất bản Y học.

2. Rivera C. Essentials of oral cancer(2015). Int J Clin Exp Pathol. 8(9):11884-11894.

3. Listl $S$, Jansen $L$, Stenzinger $A$, et al(2013). Survival of patients with oral cavity cancer in 
Germany. PLoS One. 8(1):e53415.

4. Pergolizzi S, Santacaterina A, Adamo B, et al(2011). Induction chemotherapy with paclitaxel and cisplatin to concurrent radiotherapy and weekly paclitaxel in the treatment of locoregionally advanced, stage IV (M0), head and neck squamous cell carcinoma. Mature results of a prospective study. Radiation Oncology.6(1):162.

5. Ngô Xuân Quý (2020). Nghiên cứu kết quả hóa trị bố trơ trước phác đồ TC và tỷ lệ bộc lô môt số dấu ấn liên quan đến ung thư lưỡi giai đoạn IIII-IV(M0).

6. Zhong LC, Lu F, Ma F, et al(2015). Ultrasoundguided fine-needle aspiration of thyroid nodules: does the size limit its efficiency? Int J Clin Exp Pathol.8(3):3155-3159.

7. Vokes EE, Stenson K, Rosen FR, et al(2003). Weekly carboplatin and paclitaxel followed by concomitant paclitaxel, fluorouracil, and hydroxyurea chemoradiotherapy: curative and organ-preserving therapy for advanced head and neck cancer. J Clin Oncol.

8. Zhong $L$ ping, Zhang $C$ ping, Ren $G$ xin, et al(2013). Randomized Phase III Trial of Induction Chemotherapy With Docetaxel, Cisplatin, and Fluorouracil Followed by Surgery Versus Up-Front Surgery in Locally Advanced Resectable Oral Squamous Cell Carcinoma.

9. Schwam ZG, Sosa JA, Roman S, Judson BL(2015). Complications and mortality following surgery for oral cavity cancer: analysis of 408 cases. Laryngoscope. 125(8):1869-

10. Lê Văn Quảng (2013). Nghiên cứu điều trị ung thư lưỡi giai đoan III,IV(M0) bằng cisplatin-5FU bổ trợ trước phấu thuật và/hoặc xa trị. Luận án Tiến sĩ Y hoc. Trường Đại hoc Y Hà Nội

\section{GIÁ TRI CHẨN ĐOÁN CỦA HS-TROPONIN T THỜI ĐIỂM 0- 1H Ở BÊNNH NHÂN ĐAU NGỰC ĐẾN CẤP CỨU}

\section{TÓM TẮT}

Nghiên cứu nhằm tìm hiểu giá trị của xét nghiệm hs Troponin $\mathrm{T}$ thời điểm $0-1 \mathrm{~h}$ trong chẩn đoán hối chứng vành cấp ở các bênh nhân đau ngực vào cấp cứu. Đây là một nghiên cứu mô tả cắt ngang trên 290 bệnh nhân đau ngực vào cấp cứu. Các bệnh nhân được làm 2 mẫu xét nghiệm hs troponin T lúc nhập viên và sau $1 \mathrm{~h}$ để tìm hiểu giá tri của xét nghiêm với bệnh nhân đau ngực cấp. Kết quả cho thấy tỷ lệ bệnh nhân đau ngực vào cấp cứu do HCVC găp ở $49,7 \%$ trường hợp. Giá trị và biến thiên nồng độ troponin thời điểm $0-1$ h có hiêu quả rất tốt trong chẩn đoán NMCT cấp với diện tích dưới đường cong (AUC) lần lượt là: 0,$863 ; 0,914 ; 0,932$ (với $\mathrm{p}<0.001$ ). Với ngưỡng giá tri hs troponin T lúc nhập viện là $5 \mathrm{ng} / \mathrm{l}$ để loại trừ chẩn đoán NMCT (Rule-out) thì độ nhay là 0,989 và giá trị dự báo âm tính là 94,9\%. Trong khi đó nểu lấy ngưỡng $52 \mathrm{ng} / \mathrm{l}$ để chẩn đoán NMCT (Rule-in) thì độ đặc hiệu là 0,957 giá trị dự báo dương tính là 85,6\%. Với ngưỡng biến thiên Hs-Troponin T $0-1 \mathrm{~h}$ là $5 \mathrm{ng} / \mathrm{l}$, thì độ đặc hiệu chẩn đoán NMCT là 0,957 giá trị dự báo dương tính là $88,7 \%$. Nghiên cứu cho thây xét nghiêm hs-Troponin $\mathrm{T}$ và biến thiên hs-Troponin $\mathrm{T}$ 01 h có giá trị cao trong chẩn đoán NMCT ở bệnh nhân đau ngực vào cấp cứu.

Từ khóa: Đau ngực cấp, hội chứng vành cấp, nhồi máu cơ tim cấp, Hs-Troponin T.

\section{${ }^{1}$ Bệnh viện đa khoa tỉnh Hà Nam \\ ${ }^{2}$ Trường Đại học Y Hà Nội \\ Chịu trách nhiệm chính: Nguyễn Trọng Khoa \\ Email: Drtrongkhoa@gmail.com}

Ngày nhânn bài: 7.9.2021

Ngày phản biện khoa học: 29.10.2021

Ngày duyệt bài: 8.11.2021

\section{Nguyễn Trọng Khoa ${ }^{1}$, Hoàng Bùi Hải ${ }^{2}$}

\section{SUMMARY}

DIAGNOSTIC VALUE OF HS-TROPONIN T AT 01 IH IN PATIENTS WITH CHEST PAIN COMING

TO THE EMERGENCY DEPARTMENT

The study aimed to find out the value of the hs Troponin $\mathrm{T}$ test at $0-1 \mathrm{~h}$ in the diagnosis of acute coronary syndrome in patients with chest pain entering the emergency department. This is a crosssectional descriptive study of 290 patients with chest pain presenting to the emergency department. The patients were made 2 samples of hs troponin $T$ at admission and after 1 hour to find out the value of the test for patients with chest pain. The results showed that the rate of patients with chest pain coming to the emergency department due to ACS was found in $49.7 \%$ of cases. The value and variation of troponin concentration at $0-1 \mathrm{~h}$ are very effective in diagnosing acute MI with the area under the curve (AUC) respectively: $0.863 ; 0.914 ; 0.932$ (with $p<0.001$ ). With a threshold value of hs troponin $\mathrm{T}$ at admission of $5 \mathrm{ng} / \mathrm{l}$ to exclude the diagnosis of MI (Rule-out), the sensitivity was 0.989 and the negative predictive value was $94.9 \%$. Meanwhile, if the threshold of $52 \mathrm{ng} / \mathrm{l}$ is taken to diagnose MI (Rule-in), the specificity is 0.957 , the positive predictive value is $85.6 \%$. With the threshold of variation for Hs-Troponin T 0-1h of $5 \mathrm{ng} / \mathrm{l}$, the specificity of MI diagnosis was 0.957 , the positive predictive value was $88.7 \%$. The study showed that the Hs-Troponin $\mathrm{T}$ test and the Hs-Troponin $\mathrm{T} 0-1 \mathrm{~h}$ variation had high values in diagnosing $\mathrm{MI}$ in patients with chest pain entering the emergency department.

Keywords: Acute chest pain, acute coronary syndrome, acute myocardial infarction, Hs-Troponin $\mathrm{T}$.

\section{I. ĐĂT VẤN ĐỀ}

Đau ngực là cấp cứu thường gặp tại khoa cấp 